\title{
Effect of Sodium Alginate Addition to Resveratrol on Acute Gouty Arthritis
}

\author{
Peng Wang ${ }^{a, b}$ Dunlin Ren ${ }^{c}$ Ying Chen ${ }^{b}$ Meiju Jiang ${ }^{a}$ Robin Wang ${ }^{b}$ \\ Yan-Gang Wang ${ }^{b}$
}

aDepartment of Endocrinology, Chengyang People's Hospital of Qingdao City, Qingdao, bepartment of Endocrinology, the Affiliated Hospital of Qingdao University, Qingdao, 'Emergency Department, Chengyang People's Hospital of Qingdao City Qingdao, China

\section{Key Words}

Resveratrol $\bullet$ Sodium alginate $\cdot$ Acute gouty arthritis

\begin{abstract}
Objective: Resveratrol has been shown to exert anti-inflammatory and antioxidant effects, while sodium alginate is a common pharmaceutic adjuvant with antioxidative and immunomodulatory properties. We performed an animal study to investigate the effect of sodium alginate addition to resveratrol on acute gouty arthritis. Methods: Twenty-four SPF Wistar mice were randomized to four groups receiving the combination of sodium alginate and resveratrol, resveratrol alone, colchicine, and placebo, respectively. Acute gouty arthritis was induced by injection of $0.05 \mathrm{ml}$ monosodium urate (MSU) solution $(25 \mathrm{~g} / \mathrm{mL})$ into ankle joint cavity. IL-1 $\beta$, CCR5, and CXCL10 levels in both serum and synovial fluid were measured using ELISA. NLRP3 expression in the synovial tissues was measured using western plot. Results: The combination of sodium alginate and resveratrol significantly reduced synovial levels of IL-1ß, CCR5, and CXCL10 when compared with colchicines, and all P values were less than 0.0001 . The combination of sodium alginate and resveratrol was also superior to resveratrol in terms of both serum levels and synovial levels of IL-1ß, CCR5, and CXCL10. In addition, resveratrol, with or without sodium alginate, could reduce NLRP3 expression obviously in the synovial tissues. Conclusion: The combination of sodium alginate and resveratrol has better effect over colchicines in treating MSU-induced acute gouty arthritis.
\end{abstract}




\begin{tabular}{|c|c|c|}
\hline Cellular Physiology & Cell Physiol Biochem 2015;36:201-207 & \\
\hline and Biochemistry & $\begin{array}{l}\text { DOI: 10.1159/000374064 } \\
\text { Published online: April 30, } 2015\end{array}$ & $\begin{array}{l}\text { O) } 2015 \text { S. Karger AG, Basel } \\
\text { www.karger.com/cpb }\end{array}$ \\
\hline
\end{tabular}

\section{Introduction}

Gout is a common arthritis caused by deposition of monosodium urate (MSU) crystals within joints after chronic hyperuricaemia [1]. Acute gouty arthritis is an inflammatory disease resulting from the precipitation of MSU crystals in joints and periarticular tissues, and it's a major cause of decreased quality of life in patients with gout [2, 3]. In acute gouty

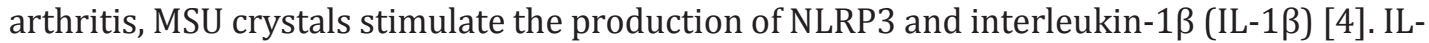
$1 \beta$ secretion can induce further production of IL- $1 \beta$ and other inflammatory mediators such as tumor necrosis factor $\alpha$ (TNF- $\alpha$ ), interleukin-6 (IL-6), and interleukin-8 (IL-8), which further lead to altered expression of adhesion molecules and chemokines, neutrophil recruitment, and a series of intense inflammation [4]. C-X-C motif chemokine 10 (CXCL10) is a $10 \mathrm{kDa}$ protein and a Th1-chemokine, which regulates immune responses through the activation and recruitment of leukocytes [5]. Recent studies have shown that CXCL10 expression is increased in various autoimmune diseases such as rheumatoid arthritis (RA) [5]. CC chemokine receptor 5 (CCR5) is a seven-transmembrane G protein-coupled receptor (GPCR) which regulates memory/effector T-lymphocytes, macrophages, and immature dendritic cells $[6,7]$. Since inflammation is a critical factor in the etiology of acute gouty arthritis and CCR5/CXCL10 have important roles in the immune responses and immunity, researches on CCR5/CXCL10 may provide new therapeutic targets for acute gouty arthritis. Resveratrol has received tremendous attention over the past couple of decades because of its benefits in several human disease models, including antioxidant effect, anti-inflammatory effect, immune regulation, and cancer chemoprevention [8-10]. Recent studies have shown that resveratrol also has good anti-inflammatory effects in rats with osteoarthritis [8, 11]. Sodium alginate is a common pharmaceutic adjuvant with antioxidative and immunomodulatory property [12-14]. We performed an animal study to investigate the effect of sodium alginate addition to resveratrol on acute gouty arthritis.

\section{Materials and Methods}

Mice

SPF Wistar male mice were from Qingdao Drug Control Institute, Qingdao, China (License number: SCXKLU20080002). All animals used for the experiments were ages 6-10 weeks with weight $180 \pm 30 \mathrm{~g}$. Twenty-four SPF Wistar mice were randomized to four groups ( 6 in each group) receiving the combination of Sodium alginate and resveratrol, resveratrol alone, colchicines, and placebo, respectively. Mice in the colchicine group was given colchicines $\left(1 \mathrm{mg} \cdot \mathrm{kg}^{-1} \cdot \mathrm{d}^{-1}\right)$, mice in the resveratrol alone group were given resveratrol $\left(500 \mathrm{mg} \cdot \mathrm{kg}^{-1} \cdot \mathrm{d}^{-1}\right)$, mice in the combination group was given resveratrol $\left(500 \mathrm{mg} \cdot \mathrm{kg}^{-1} \cdot \mathrm{d}^{-1}\right)$ and sodium alginate $500 \mathrm{mg} \cdot \mathrm{kg}^{-1} \cdot \mathrm{d}^{-1}$, while the placebo group was given normal saline. The experiments were approved by the Qingdao University Animal Ethics Committee and carried out in accordance with the Committee's guidelines for the care of animals.

\section{Preparation of MSU solution}

$1 \mathrm{~g}$ uric acid was boiled in $200 \mathrm{ml}$ of $\mathrm{NaOH}(6 \mathrm{ml}, 1 \mathrm{~N}) /$ double-distilled water (194 ml) until completely dissolved. The PH of uric acid solution was adjusted to 7.2 with HCL (1N). The uric acid solution was then filtered sterile $\left(0.2-\mu \mathrm{m}\right.$ filter) and stored at $4^{\circ} \mathrm{C}$ for 24 hours to allow crystal formation. The resulting MSU crystals were then washed and air-dried under sterile conditions. $250 \mathrm{mg}$ MSU crystals were added to 10 $\mathrm{ml}$ of saline $(9 \mathrm{ml}) /$ Polysorbate $-80(1 \mathrm{ml})$, and the solution was further heated and stirred, leading to $10 \mathrm{ml}$ solution of MSU $(25 \mathrm{mg} / \mathrm{ml})$.

Model of MSU-induced acute gouty arthritis

After 4-day gavage, all mice were weighed again. $1 \mathrm{~h}$ after the last gavage and prior to MSU injection, the right ankle circumference was measured with tie-line method. In all four groups, acute gouty arthritis was induced by injection of $0.05 \mathrm{ml}$ MSU solution $(25 \mathrm{~g} / \mathrm{mL})$ into the right ankle joint cavity. 


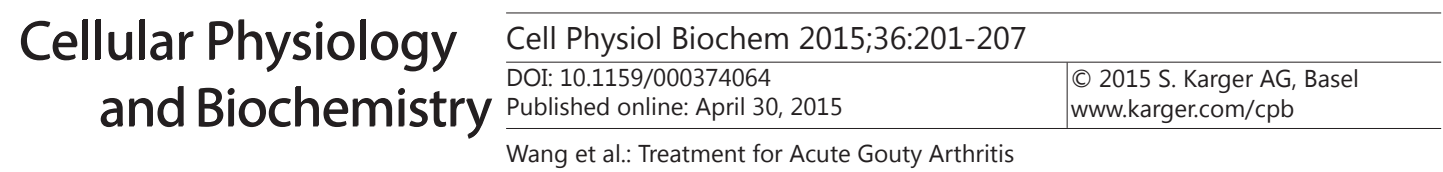

Joint swelling index

After MSU injection, the right ankle circumference was measured at the same position with tie-line method at $0 \mathrm{~h}, 3 \mathrm{~h}, 6 \mathrm{~h}, 24 \mathrm{~h}, 48 \mathrm{~h}$, and $72 \mathrm{~h}$. The degree of joint swelling was measured by the joint swelling index, which was calculated as the following: (Circumference at test point - Initial Circumference)/Initial Circumference. The bigger joint swelling index was, the more serious joint swelling was.

Measurement of IL-1 $\beta$, CCR5, and CXCL10

The levels of IL-1 $\beta$, CCR5, and CXCL10 in both the serum and the synovial fluid were measured by ELISA. Serum levels of IL-1 $\beta$ were measured at $9 \mathrm{~h}$ after MSU injection, while serum levels of CCR5 and CXCL10 were measured at $48 \mathrm{~h}$ after MSU injection. The levels of IL-1 $\beta$, CCR5, and CXCL10 in the synovial fluid were also measured at $72 \mathrm{~h}$ after MSU injection.

NLRP3 expression in synovial tissues

NLRP3 expression was measured by BCA method through the homogenate of synovial tissues of right ankle joints in ice bath. After electrophoresis of 12\% SDS-PAGE, NLRP3 was transferred to PVDF membrane, and then was blocked by $5 \%$ nonfat milk powder for 2 hours. Primary antibody incubation was then overnight performed with the corresponding antibodies of NLRP3 and $\beta$-actin at $4{ }^{\circ} \mathrm{C}$. After washing by PBST and PBS, the secondary antibody incubation was further performed using corresponding secondary antibodies. The NLRP3 protein was developed using electrochemiluminescence reagent, and the density of each band was measured by densitometry using Quantity One software according to the manufacturer's instructions. Levels of target proteins were normalized to $\beta$-actin values.

\section{Statistical analysis}

The statistical analyses were performed using SPSS 17.0. Comparisons between the treatment groups were analyzed by two-tailed Student's t test. Results are expressed as the mean \pm standard error of the mean (SEM). $\mathrm{P}$ value $>0.05$ was considered as statistically significant.

\section{Results}

MSU-induced joint swelling

There was no obvious difference in the joint swelling index of mice among all those four groups at baseline ( $\mathrm{P}>0.05)$. The combination of sodium alginate and resveratrol significantly suppressed the MSU-induced joint swelling when compared with resveratrol alone at $6 \mathrm{~h}$ after MSU injection ( $\mathrm{P}=0.007)$. However, there was no obvious difference in the MSU-induced joint swelling at $6 \mathrm{~h}$ between the combination and the colchicine group (P > 0.05). At 24h after MSU injection, all three treatment groups had significantly lower MSUinduced joint swelling than that in the placebo group $(\mathrm{P}<0.05)$, while there was no obvious difference in those three treatment groups $(\mathrm{P}>0.05)$ (Fig. 1).

Fig. 1. Joint swelling index after MSU injection in those four groups (Data were means \pm SEM from 4 separate experiments. ${ }^{*} \mathrm{P}<0.05$ versus the Placebo group).

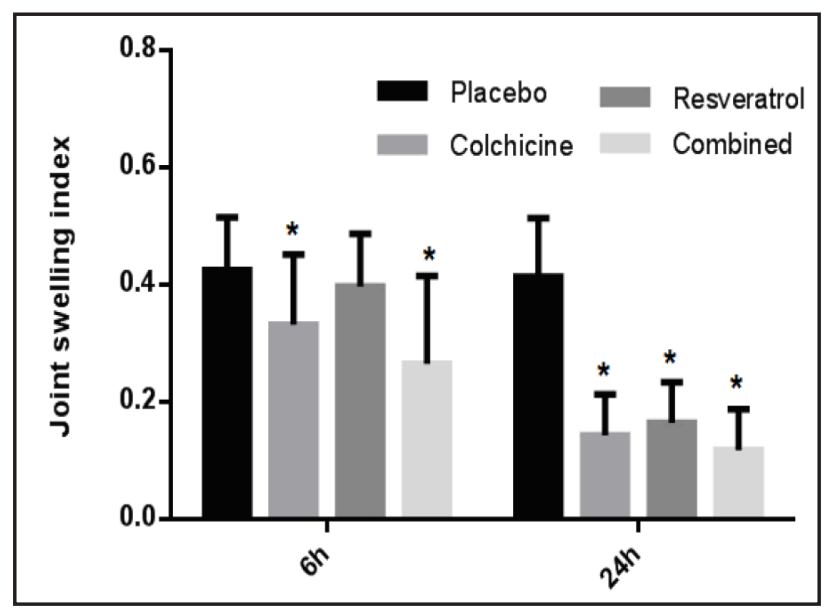




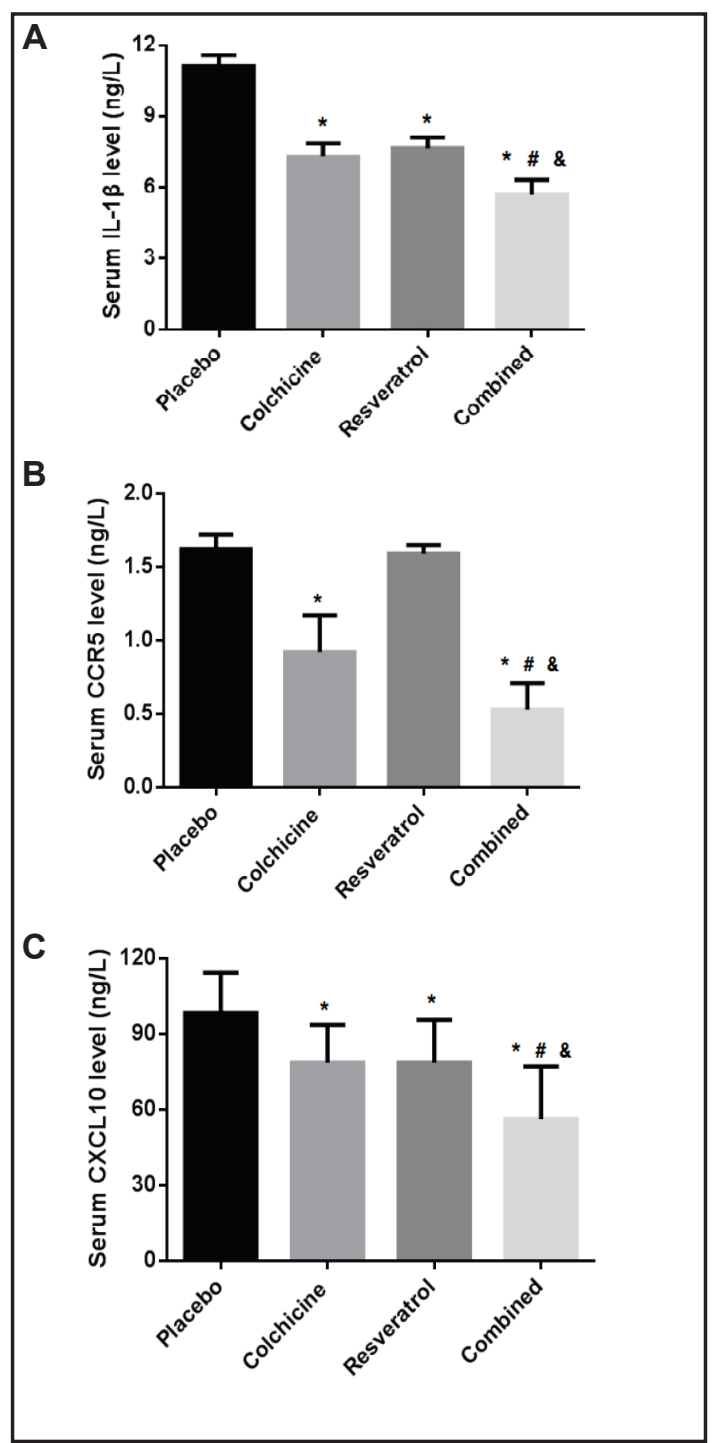

Fig. 2. Serum IL-1 $\beta$, CCR5 and CXCL10 levels in those four groups (Data were means \pm SEM from 4 separate experiments. ${ }^{*} \mathrm{P}<0.05$ versus the Placebo group; \# $\mathrm{P}<0.05$ versus the Colchicine group; $\& \mathrm{P}<0.05$ versus the Resveratrol group). (A) Serum level of IL-1 $\beta$ in each group. (B) Serum level of CCR5 in each group. (C) Serum level of CXCL10 in each group

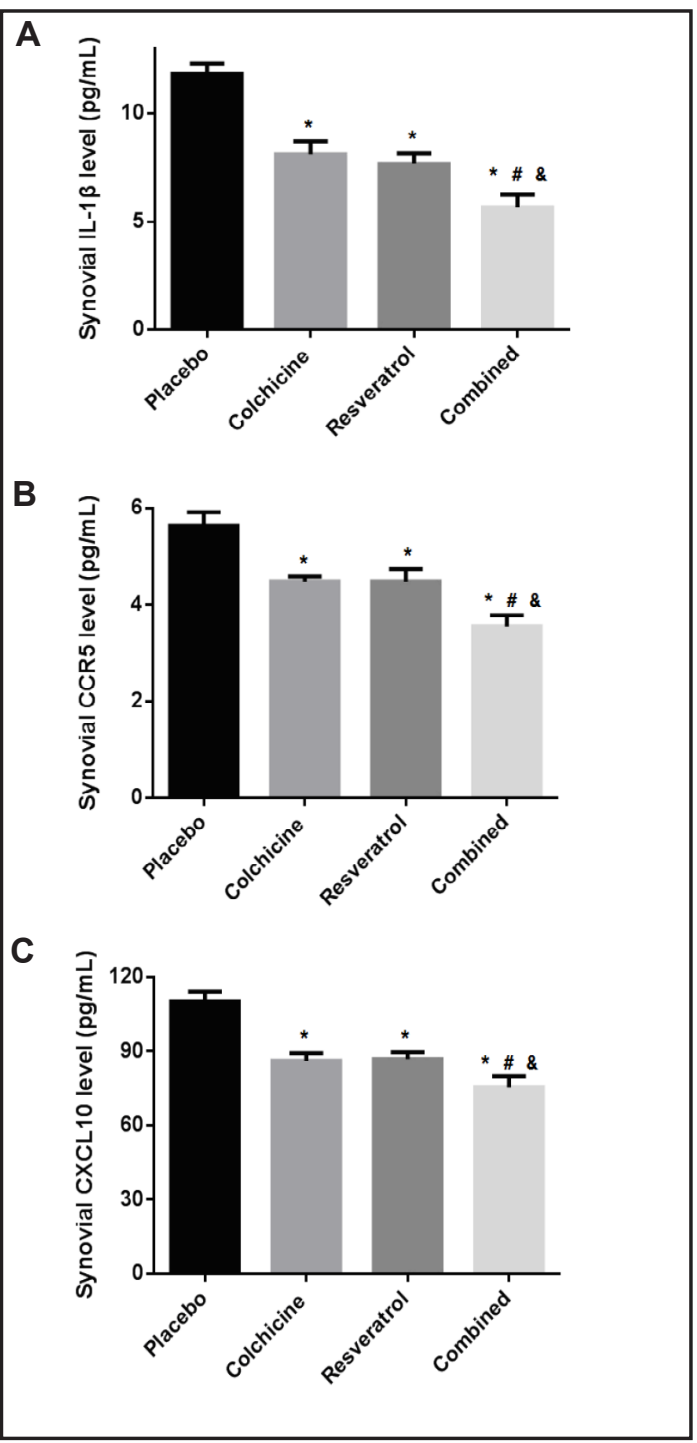

Fig. 3. Comparison of IL-1 $\beta$, CCR5, and CXCL10 levels in the synovial fluid in each group (Data were means \pm SEM from 4 separate experiments. ${ }^{*} \mathrm{P}<0.05$ versus the Placebo group; \# $\mathrm{P}<0.05$ versus the Colchicine group; \& $\mathrm{P}<0.05$ versus the Resveratrol group). (A) Synovial level of IL-1 $\beta$ in each group. (B) Synovial level of CCR5 in each group. (C) Synovial level of CXCL10 in each group.

Levels of IL-1 $\beta$, CCR5, and CXCL10 in serum and synovial fluid

The combination of sodium alginate and resveratrol significantly reduced serum levels of IL-1 $\beta$, CCR5, and CXCL10 when compared with colchicines, and the P values were 0.0001 , 0.002 and 0.03 , respectively (Fig. 2). In addition, the combination of sodium alginate and resveratrol was also superior to resveratrol in terms of serum levels of IL-1 $\beta$, CCR5, and CXCL10 (Fig. 2).

The combination of sodium alginate and resveratrol significantly reduced synovial levels of IL-1 $\beta$, CCR5, and CXCL10 when compared with colchicines, and all three P values were less than 0.0001 (Fig. 3). In addition, the combination of sodium alginate and resveratrol was also superior to resveratrol alone in decreasing synovial levels of IL-1 $\beta$, CCR5, and CXCL10 (Fig. 3). 
Fig. 4. Comparison of NLRP3 expression in the synovial tissues (Data were means \pm SEM from 4 separate experiments. ${ }^{*} \mathrm{P}<0.05$ versus the Placebo group; \# $\mathrm{P}<0.05$ versus the Colchicine group).

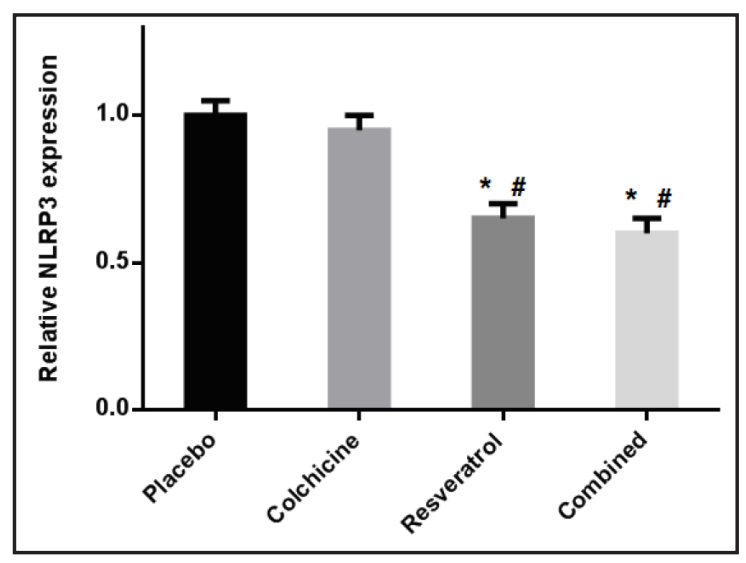

NLRP3 expression in synovial tissues

As shown in the Fig. 4, compared with the colchicines group, resveratrol, with or without sodium alginate, could reduce NLRP3 expression obviously in the synovial tissues of mice with acute gouty arthritis ( $\mathrm{P}<0.05$, Fig. 4).

\section{Discussion}

Gout is a common arthritis caused by deposition of monosodium urate (MSU) crystals within joints after chronic hyperuricaemia [1]. Obesity and hypertriglyceridemia have been identified as risk factors of gout $[15,16]$. As the rapid increasing incidence of obesity and hypertriglyceridemia in the population [17-19], the gout's prevalence will increase obviously. Currently, there is still lack of effective treatment for acute gouty arthritis, and more researches are needed to further develop promising drugs.

In acute gouty arthritis, MSU crystals activate the NLRP3 inflammasome which further leads to IL-1 $\beta$ secretion $[4,20,21]$. It's has been well known that NLRP3 and IL-1 $\beta$ is key mediators of the inflammatory response and it plays a central role in the MSU-induced inflammation in the development of acute gouty arthritis. In present study, we found that resveratrol, with or without sodium alginate, could reduce NLRP3 expression obviously in the synovial tissues of mice with acute gouty arthritis (Fig. 4). The finding above indicates that resveratrol may treat acute gouty arthritis through inhibiting NLRP3 expression.

IL-1 $\beta$ can induce the expression of endothelial cells, increase the activity of macrophages and granulocytes, and stimulate monocyte-macrophages to express IL-6, IL-8 and TNF- $\alpha$ and other secondary inflammatory cytokines [4]. Therefore, inhibition of IL-1 $\beta$ is a promising treatment of acute gouty arthritis, and some effective biologic agents targeting IL- $1 \beta$ have been developed against acute gouty arthritis such as IL-1 $\beta$ antagonist Canakinumab. In present study, the combination of sodium alginate and resveratrol significantly reduced serum levels of IL-1 $\beta$ when compared with colchicines or resveratrol alone. The superior effect in the combination group suggests that sodium alginate in combination with resveratrol is a promising therapeutic method for acute gouty arthritis by the anti-inflammatory effect.

Chemokines coordinate leukocyte migration in immunity and inflammation and have been implicated in the pathogenesis of many human diseases [22, 23]. Both CCR5 and CXCL10 are important chemokines and can regulate immune responses through the activation and recruitment of immune cells, such as T-lymphocytes, macrophages, and immature dendritic cells $[22,23]$. Previous studies have shown that both CCR5 and CXCL10 are involved in the development of arthritis [24, 25]. During the development of gouty arthritis, chemokines and its receptor, such as CCR5 and CXCL10, may play important roles in the inflammatory reactions or tissue damages. Considering the important roles of CCR5/CXCL10 in the development of gouty arthriti, drugs targeting CCR5/CXCL10 may new therapeutics for acute gouty arthritis [26]. In our study, the combination of sodium alginate and resveratrol 


\begin{tabular}{|c|c|c|}
\hline Cellular Physiology & Cell Physiol Biochem 2015;36:201-207 & \\
\hline and Biochemistry & $\begin{array}{l}\text { DOI: 10.1159/000374064 } \\
\text { Published online: April 30, } 2015\end{array}$ & $\begin{array}{l}\text { O } 2015 \text { S. Karger AG, Basel } \\
\text { www.karger.com/cpb }\end{array}$ \\
\hline
\end{tabular}

significantly reduced the levels of CCR5 and CXCL10 in both the serum and the synovial fluid when compared with colchicines or resveratrol alone (Fig. 2, Fig. 3). The outcomes above further prove the superior effect of sodium alginate in combination with resveratrol over colchicines alone or resveratrol alone. However, the findings in our study need the validation from clinical trials. Currently, there is no clinical trials aimed to assess the treatment effect of the combination of sodium alginate and resveratrol on acute gouty arthritis, and further clinical trials are needed to assess the promising effect.

In summary, the combination of sodium alginate and resveratrol has better effect over colchicines in treating MSU-induced acute gouty arthritis. However, more studies are needed to further explore the mechanism underline the effects of resveratrol and sodium alginate on gouty arthritis. In addition, further clinical trials are needed to validate the finding in present study.

\section{Disclosure Statement}

We declare that we have no conflicts of interest.

\section{References}

1 Rock KL, Kataoka H, Lai JJ: Uric acid as a danger signal in gout and its comorbidities. Nat Rev Rheumatol 2013;9:13-23.

2 Kietthubthew S, Sriplung H, Au WW, Ishida T: Polymorphism in DNA repair genes and oral squamous cell carcinoma in thailand. Int J Hyg Environ Health 2006;209:21-29.

3 Yadav BK, Kaur J, Srivastava A, Ralhan R: Effect of polymorphisms in xrcc1, ccnd1 and gstm 1 and tobacco exposure as risk modifier for oral leukoplakia. Int J Biol Markers 2009;24:90-98.

4 Schlesinger N, Thiele RG: The pathogenesis of bone erosions in gouty arthritis. Ann Rheum Dis 2010;69:1907-1912.

5 Laragione T, Brenner M, Sherry B, Gulko PS: Cxcl10 and its receptor cxcr3 regulate synovial fibroblast invasion in rheumatoid arthritis. Arthritis Rheum 2011;63:3274-3283.

6 Mackay CR, Sallusto F: A new role for ccr5 in innate immunity--binding to bacterial heat shock protein 70. Eur J Immunol 2006;36:2293-2295.

7 Lederman MM, Sieg SF: Ccr5 and its ligands: A new axis of evil? Nat Immunol 2007;8:1283-1285.

8 Pervaiz S, Holme AL: Resveratrol: Its biologic targets and functional activity. Antioxid Redox Signal 2009;11:2851-2897.

9 Lagouge M, Argmann C, Gerhart-Hines Z, Meziane H, Lerin C: Resveratrol improves mitochondrial function and protects against metabolic disease by activating sirt1 and pgc-1alpha. Cell 2006;127:1109-1122.

10 Baur JA, Pearson KJ, Price NL, Jamieson HA, Lerin C: Resveratrol improves health and survival of mice on a high-calorie diet. Nature 2006;444:337-342.

11 Dave M, Attur M, Palmer G, Al-Mussawir HE, Kennish L, Patel J, Abramson SB: The antioxidant resveratrol protects against chondrocyte apoptosis via effects on mitochondrial polarization and atp production. Arthritis Rheum 2008;58:2786-2797.

12 Sen M: Effects of molecular weight and ratio of guluronic acid to mannuronic acid on the antioxidant properties of sodium alginate fractions prepared by radiation-induced degradation. Appl Radiat Isot 2011;69:126-129.

13 Dobakhti F, Naghibi T, Taghikhani M, Ajdary S, Rafinejad A, Bayati K, Rafiei S, Rafiee-Tehrani M: Adjuvanticity effect of sodium alginate on subcutaneously injected bcg in balb/c mice. Microbes Infect 2009;11:296-301.

14 Mirshafiey A, Borzooy Z, Abhari RS, Razavi A, Tavangar M, Rehm BH: Treatment of experimental immune complex glomerulonephritis by sodium alginate. Vascul Pharmacol 2005;43:30-35.

15 Chen JH, Pan WH, Hsu CC, Yeh WT, Chuang SY, Chen PY, Chen HC, Chang CT, Huang WL: Impact of obesity and hypertriglyceridemia on gout development with or without hyperuricemia: A prospective study. Arthritis Care Res (Hoboken) 2013;65:133-140. 


\section{Cellular Physiology Cell Physiol Biochem 2015;36:201-207 \begin{tabular}{ll|l} 
DOI: 10.1159/000374064 & $\begin{array}{l}\text { O 2015 S. Karger AG, Basel } \\
\text { www.karger.com/cpb }\end{array}$ \\
\hline and Biochemistry & Published online: April 30, 2015 &
\end{tabular} \\ Wang et al.: Treatment for Acute Gouty Arthritis}

16 Cea Soriano L, Rothenbacher D, Choi HK, Garcia Rodriguez LA: Contemporary epidemiology of gout in the uk general population. Arthritis Res Ther 2011;13:R39.

17 Hall KD, Butte NF, Swinburn BA, Chow CC: Dynamics of childhood growth and obesity: Development and validation of a quantitative mathematical model. Lancet Diabetes Endocrinol 2013;1:97-105.

18 Hegele RA, Ginsberg HN, Chapman MJ, Nordestgaard BG, Kuivenhoven JA: The polygenic nature of hypertriglyceridaemia: Implications for definition, diagnosis, and management. Lancet Diabetes Endocrinol 2014;2:655-666.

19 Rivera JA, de Cossio TG, Pedraza LS, Aburto TC, Sanchez TG, Martorell R: Childhood and adolescent overweight and obesity in latin america: A systematic review. Lancet Diabetes Endocrinol 2014;2:321-332.

20 Chhana A, Callon KE, Pool B, Naot D, Watson M, Gamble GD, McQueen FM, Cornish J, Dalbeth N: Monosodium urate monohydrate crystals inhibit osteoblast viability and function: Implications for development of bone erosion in gout. Ann Rheum Dis 2011;70:1684-1691.

21 Giamarellos-Bourboulis EJ, Mouktaroudi M, Bodar E, van der Ven J, Kullberg BJ, Netea MG, van der Meer JW: Crystals of monosodium urate monohydrate enhance lipopolysaccharide-induced release of interleukin 1 beta by mononuclear cells through a caspase 1-mediated process. Ann Rheum Dis 2009;68:273-278.

22 Griffith JW, Sokol CL, Luster AD: Chemokines and chemokine receptors: Positioning cells for host defense and immunity. Annu Rev Immunol 2014;32:659-702.

23 Turner MD, Nedjai B, Hurst T, Pennington DJ: Cytokines and chemokines: At the crossroads of cell signalling and inflammatory disease. Biochim Biophys Acta 2014;1843:2563-2582.

24 Toyoda Y, Tabata S, Kishi J, Kuramoto T, Mitsuhashi A, Saijo A, Kawano H: Thymidine phosphorylase regulates the expression of cxcl10 in rheumatoid arthritis fibroblast-like synoviocytes. Arthritis Rheumatol 2014;66:560-568.

25 Duan H, Yang P, Fang F, Ding S, Xiao W: Ccr5 small interfering rna ameliorated joint inflammation in rats with adjuvant-induced arthritis. Immunol Lett 2014;162:258-263.

26 Lee EY, Lee ZH, Song YW: The interaction between cxcl10 and cytokines in chronic inflammatory arthritis. Autoimmun Rev 2013;12:554-557. 